\title{
DISTRIBUTION OF SODIUM AND POTASSIUM AND ITS RELATION TO SPERM CONCENTRATION IN THE EPIDIDYMAL PLASMA OF THE BULL
}

\author{
B. GRABO AND B. GUSTAFSSON \\ Department of Clinical Biochemistry and Department of Obstetrics and \\ Gynaecology, Royal Veterinary College, Stockholm 50, Sweden
}

(Received 24th October 1963)

\begin{abstract}
Summary. Sodium and potassium were measured in epididymal plasma at six different levels of the epididymal duct in individual bulls, and the sperm concentration was estimated at the same levels. The sperm concentration was very low in the rete testis and the proximal part of the caput, but increased continuously to a maximum at the proximal end of the corpus. It fluctuated thereafter, being lower in the distal corpus and slightly higher in the cauda. In the rete testis the sodium content of the plasma was high and the potassium content low. The concentration of sodium decreased in the caput and proximal part of the corpus, where the potassium concentration reached its maximum, thus indicating a selective resorption of sodium with the fluid. In the rest of the corpus the concentration of sodium and potassium remained unchanged but in the cauda the concentration of both decreased markedly.
\end{abstract}

\section{INTRODUCTION}

It has been known for a long time that the epididymis plays an important role in the development of spermatozoa to fully fertile cells. The mechanism of this so-called maturation process is, however, not completely known. Attempts have been made to clarify it through studies of the environment in the epididymal duct (cf. Bishop \& Walton, 1960; Bishop, 1961). The sodium and potassium concentration in testicular and epididymal contents have been investigated in bulls, rams and goats by Salisbury \& Cragle (1956), Sørensen \& Andersen (1956), Cragle, Salisbury \& VanDemark (1958), Cragle, Salisbury \& Muntz (1958), White, Wallace, Wales \& Scott (1961) and Scott, Wales, Wallace \& White (1963). However, these investigations, probably owing to limitations of the available methods, depended on either an analysis of the total contents in the epididymis or on pooled samples of sperm-free epididymal plasma. Thus it has not been possible to demonstrate by chemical methods potential disturbances in epididymal function, such as Gustafsson (1964) described. The results reported by Swanson \& Boyd (1962) concerning the origin of certain tail defects in bull spermatozoa may also indicate a disturbance in the epididymal function.

Nicander $(1957,1958)$ has divided the epididymis into different regions 337 
mainly according to the epithelial structure and considers that the different regions may have different functions. A systematic chemical investigation of potential regional differences in individual animals has not previously been reported in the literature. We have begun a systematic investigation (see preliminary communication, Crabo \& Gustafsson, 1963) of epididymal plasma from individual bulls with the aid of Sanz's (1959) ultramicrotechnique. This paper is a report of the results of analyses of sodium and potassium concentrations in different epididymal regions combined with estimations of the sperm concentration in the same regions.

The following terms are used in what follows: 'Epididymal content' is the total content in a certain part of the epididymal duct, i.e. fluid +sperm. 'Epididymal plasma' is the supernatant after centrifugation of epididymal content. 'Epididymal sperm' is the sediment after centrifugation of epididymal content, and is mainly composed of spermatozoa.

\section{MATERIAL AND METHODS}

A total of twenty-two epididymides from seventeen bulls of the Swedish Red and White breed were investigated. The bulls were said to have normal fertility.

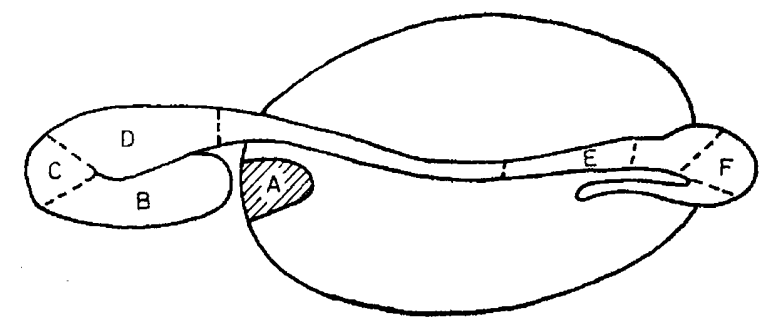

TexT-FIG. 1. Schematic drawing of the right testis and epididymis of a bull with the proximal third of the epididymis dissected free from the testis and stretched out. The designations $\mathrm{A}$ to $\mathrm{F}$ indicate the different sections from which epididymal contents were collected.

The eight bulls from which semen samples could be obtained presented a normal semen picture according to Lagerlöf's (1934, 1962) classification.

Testes and epididymides were obtained at slaughter. The epididymal contents were removed immediately and were stored in teflon tubes. The analyses were performed immediately after return to the laboratory. The material from the epididymis was collected from different sections which were chosen with the guidance of Nicander's (1958) division of the epididymis into regions on a morphological basis as shown in Text-fig. 1. The material from the rete testis (A) was obtained by dissecting and puncturing the border between the testis and the caput epididymidis. The contents of the remaining sections (B to F) were collected by careful dissection and puncture. After blotting the tissue fluids, luminal contents were sucked up with fine teflon pipettes. Smears were made to check if a large number of epithelial and blood cells were included and that the morphology of the spermatozoa was normal.

The sperm concentration was expressed in volume per cent packed cells (spermatocrit) and was obtained by centrifuging the epididymal content at 
$12,000 \mathrm{rev} / \mathrm{min}$ in a Beckman 'Microfuge' for $5 \mathrm{~min}$ in a teflon tube. The epididymal plasma obtained by centrifuging the epididymal content was used for the analysis of sodium and potassium. With the aid of Sanz's (1959) micropipettes 5 or $10 \mu \mathrm{l}$ of plasma were measured and diluted with an automatic pipette to $1: 300$ or $1: 150$, respectively. The analyses were done with an EEL flame photometer. The solutions were checked against standard solutions. Duplicate measurements were made to estimate the error involved. The random errors (calculated from the formula $\sqrt{\frac{\Sigma(a-b)^{2}}{2 n}}$, where $a$ and $b$ denote the separate values in a duplicate determination and $n$ the number of duplicate determinations) for a single determination were the following: spermatocrit $1.7 \%$, sodium 1.9 m-equiv. $/ 1$, and potassium 0.7 m-equiv. $/ 1$. Standard statistical methods have been used for all calculations (Snedecor, 1946).

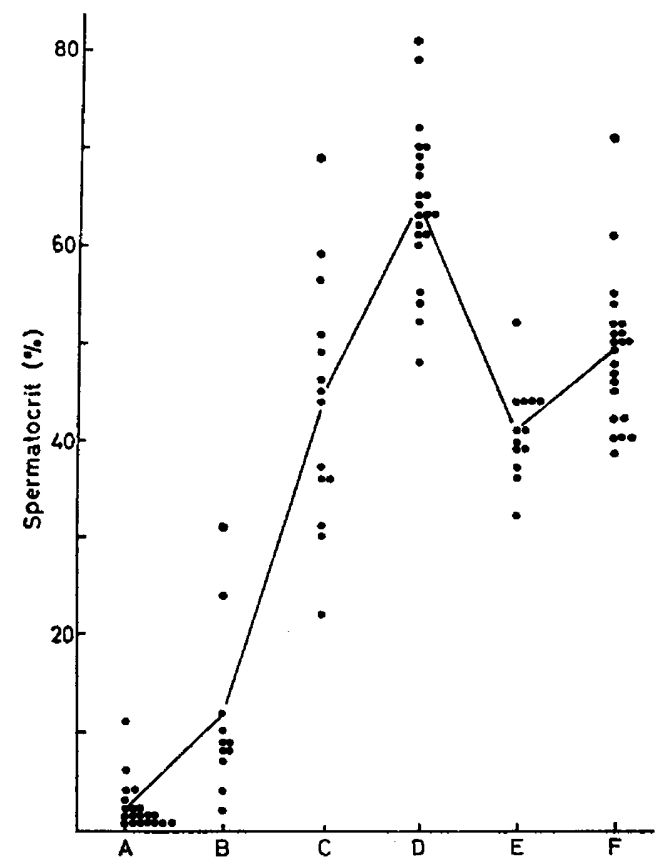

TexT-Frg. 2. Spermatocrit values in different levels of the epididymal duct. Each point represents one analysis and the line the mean value.

\section{RESULTS}

\section{SPERM CONCENTRATION}

The variation of the spermatocrit between the various epididymal sections can be seen in Table 1 and Text-fig. 2. The fluid from the rete testis has, on the average, a spermatocrit of $2 \%$. The sperm concentration increased in the subsequent sections and reached a maximum (64\%) in Section D. The concentration then dropped to $41 \%$ in the corpus and increased again to $49 \%$ in the cauda epididymidis. 


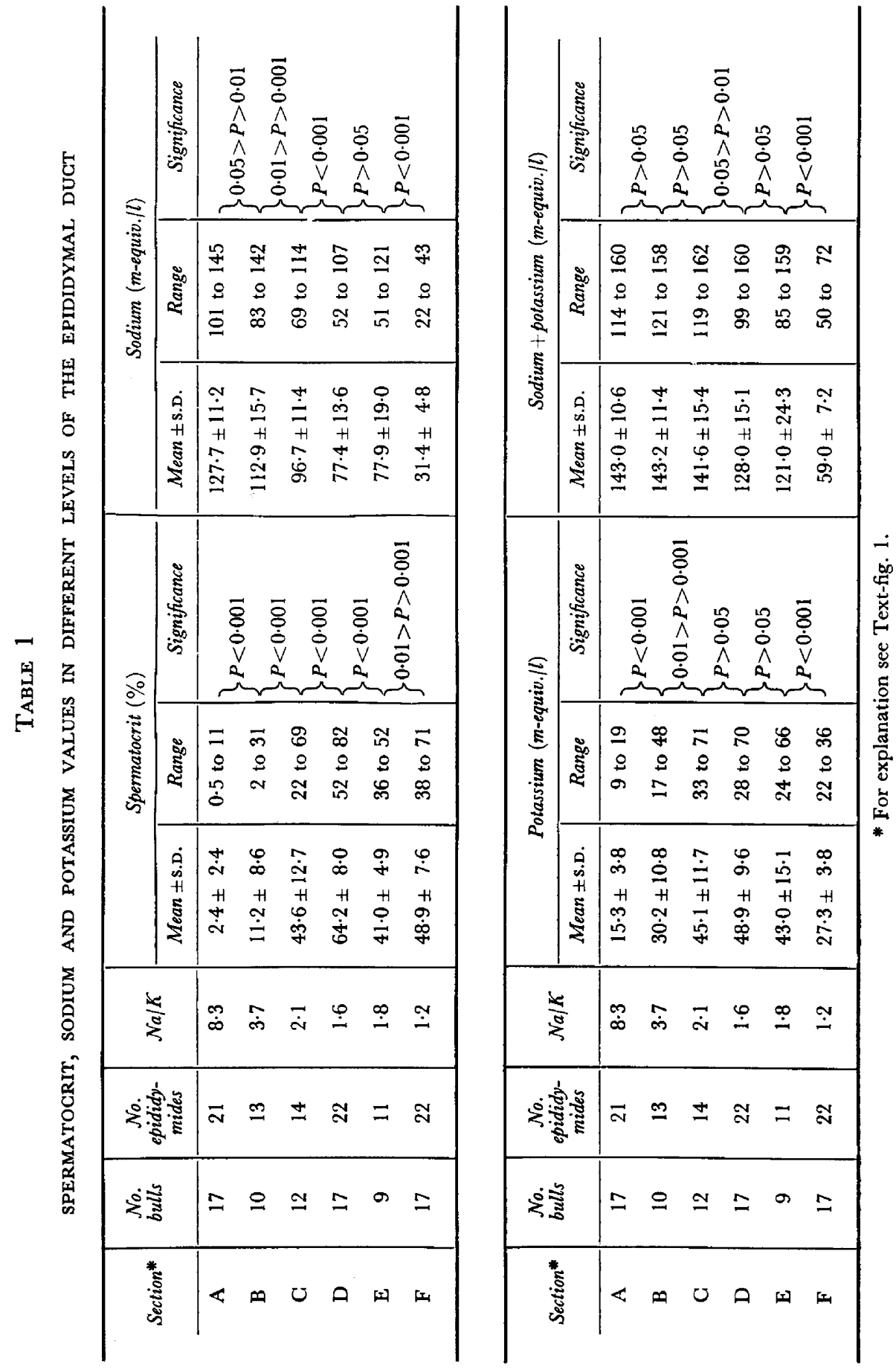




\section{SODIUM AND POTASSIUM}

The sodium and potassium values obtained during the analyses appear in Table 1 and Text-figs. 3 and 4 . In the rete testis there was 127.7 m-equiv./l of sodium and in the proximal caput 112.9 m-equiv./l $(P<0 \cdot 05)$. The sodium

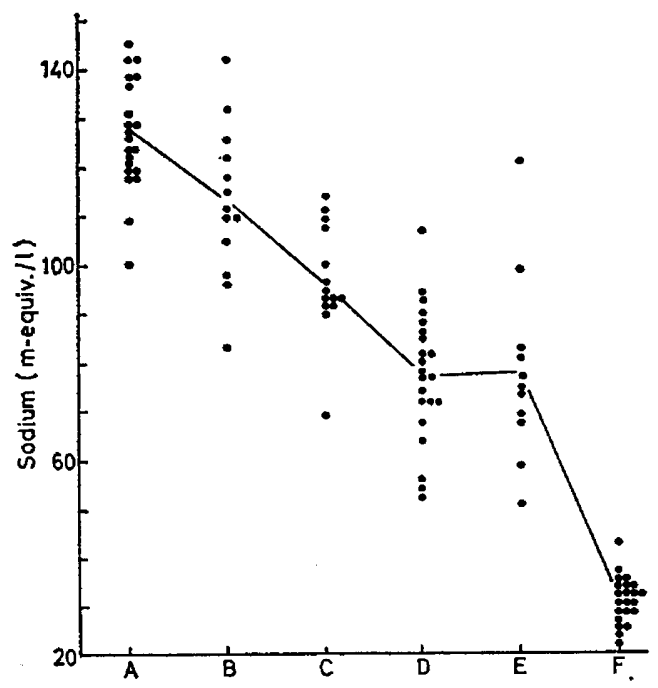

Text-fig. 3. Sodium values in different levels of the epididymal duct. Each point represents one analysis and the line the mean value.

content in Section C (96.7 m-equiv./1) differed from the level in the proximal caput $(P<0.01)$ and in the corpus $(77.4$ and 77.9 m-equiv. $/ 1, P<0.001)$. The lowest concentration of sodium was in the cauda epididymidis $(31.4 \mathrm{~m}$-equiv./1).

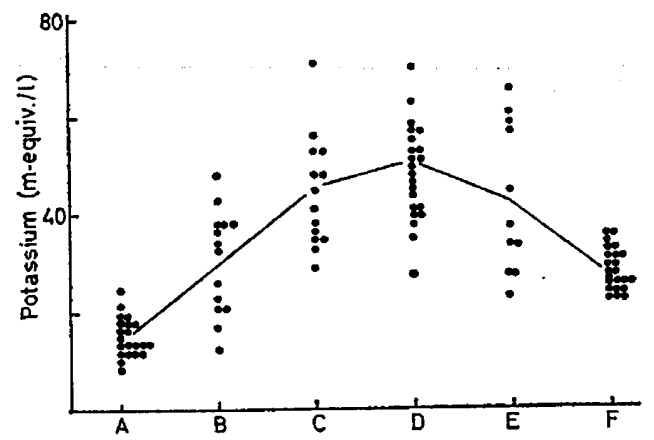

Text-fig. 4. Potassium values in different levels of the epididymal duct. Each point represents one analysis and the line the mean value.

The potassium concentration, on the other hand, was lowest in the rete testis $(15.3 \mathrm{~m}$-equiv./1). The concentration was $30.2 \mathrm{~m}$-equiv./1 $(P<0.001)$ in the proximal caput and $45.1 \mathrm{~m}$-equiv. $/ 1$ in Section $\mathrm{C}(P<0.01)$. The concentration in the corpus was the same as in Section $C$ but there was only 27.3 m-equiv./1 of potassium in the cauda $(P<0.001)$. 
In the rete testis and caput epididymidis the sum of the concentration of sodium and potassium is nearly constant (about 140 m-equiv./l). In Section D the sum is 128 m-equiv./1 and in Section $\mathrm{E} 121 \mathrm{~m}$-equiv./l, both values being lower than in the first three sections $(P<0.05)$ and higher than in the cauda epididymidis (59 m-equiv. $/ 1, P<0.001$ ).

The quotient of sodium/potassium (Table 1) diminishes very rapidly in the first three sections from $8 \cdot 3$ to $2 \cdot 1$. Between Sections $C$ and D a low reduction occurs and the quotient is, by and large, unchanged in Section $E$. Then the quotient diminishes a little in Section $\mathrm{F}$ where it is 1.2 .

\section{DISCUSSION}

The range of the values, as is shown by Table 1 and Text-figs. 2 to 5 , is relatively great within each section. This is particularly true of Section $\mathrm{C}$ and can probably

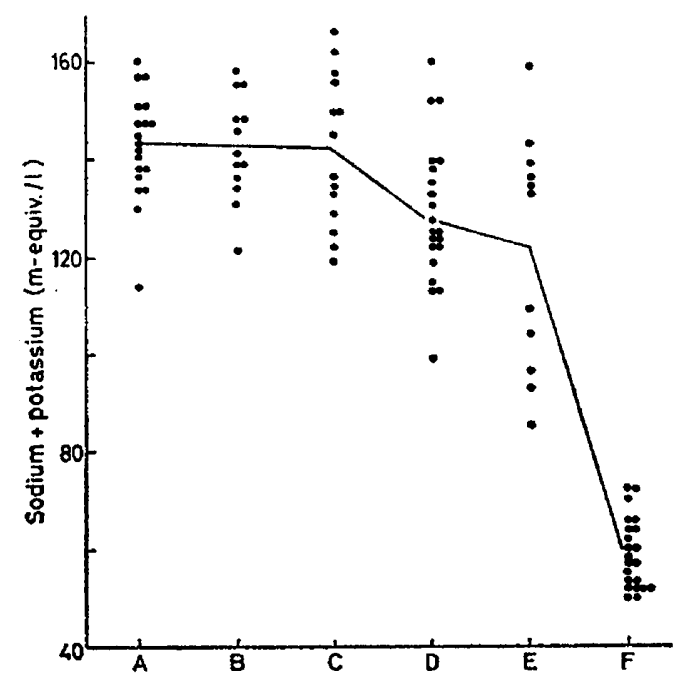

TexT-rig. 5. Sodium + potassium values in different levels of the epididymal duct. Each point represents one analysis and the line the mean value.

be explained by the collecting procedure. In order to obtain reliable amounts of test material, a relatively large number of punctures must be made within each section. In addition, the character of the contents, both in relation to spermatozoa and electrolytes, changes along the length of the epididymis. Thus it is clear that variations in the results can occur. It is also rather difficult to find exactly the same collection point at every collection attempt; this naturally also contributes to a larger range of the values. In Sections A and F, however, a greater amount of epididymal contents can be obtained from every puncture and consequently the range of the values is less.

As a result of histological investigations, it has long been known that sperm concentration takes place in the head of the epididymis (see Nicander, 1957). Observing, by histological techniques, the changes in the density of the spermatozoa in the epididymal lumen of bulls, Nicander (1958) assumed that the 
epididymal contents were chiefly concentrated in Regions 3 and 4 (these most closely correspond to Sections C and D). He thought that the concentration remained unchanged in the corpus epididymidis but that dilution probably took place in the cauda epididymidis. The present investigation clearly shows a continual fluid resorption in the entire caput epididymidis with a maximal concentration of epididymal contents in Section D. A comparatively great dilution then occurs in the corpus. The contents concentrate again in the cauda epididymidis. In rabbits Nicander (1957) found a great dilution of the luminar contents in his Region 5 (probably corresponding to the distal part of the corpus epididymidis of the bull); the sperm concentration increased in the cauda. According to the present investigation the condition in the bull epididymis seems to be similar.

TABLE 2

COMPARISON BETWEEN PRESENT AND EARLIER INVESTIGATION OF THE EPIDIDYMAL CONTENTS

\begin{tabular}{|c|c|c|c|c|c|c|c|c|c|}
\hline \multirow{3}{*}{ Species } & \multirow{2}{*}{\multicolumn{2}{|c|}{ Testis }} & \multicolumn{6}{|c|}{ Epididymis } & \multirow{3}{*}{ Reference } \\
\hline & & & \multicolumn{2}{|c|}{ Caput } & \multicolumn{2}{|c|}{ Corpus } & \multicolumn{2}{|c|}{ Cauda } & \\
\hline & $\mathcal{N a}$ & $\kappa$ & $N a$ & $\kappa$ & $\mathcal{N} a$ & $\kappa$ & $\mathcal{N} a$ & $\kappa$ & \\
\hline $\begin{array}{l}\text { Bull* } \\
\text { Bull* } \\
\text { Bull† } \\
\text { Ram† } \\
\text { Ram† } \\
\text { Bull† }\end{array}$ & $\begin{array}{r}48 \\
77 \\
- \\
166 \\
166 \\
128\end{array}$ & $\begin{array}{r}96 \\
- \\
\overrightarrow{28} \\
28 \\
15\end{array}$ & $\begin{array}{c}102 \\
- \\
\overline{90} \\
90 \\
113,97,77 \div\end{array}$ & $\mid \begin{array}{c}50 \\
- \\
- \\
49 \\
49 \\
30,45,49 \ddagger\end{array}$ & $\begin{array}{l}\overline{-} \\
\overline{-} \\
\overline{78}\end{array}$ & $\begin{array}{l}- \\
\overline{-} \\
\overline{-} \\
\overline{43}\end{array}$ & $\begin{array}{c}39 \\
\overline{-} \\
40 \\
57,40 \\
31\end{array}$ & $\mid \begin{array}{c}45 \\
- \\
25 \\
29 \\
39,29 \neq \\
27\end{array}$ & $\begin{array}{l}\text { Salisbury \& Cragle (1956) } \\
\text { Cragle } \text { et al. (1958) } \\
\text { Sørensen \& Andersen (1956) } \\
\text { White } \text { et al. (1961) } \\
\text { Scott } \text { et al. (1963) } \\
\text { Present investigation }\end{array}$ \\
\hline
\end{tabular}

Mean values given in m-equiv./1.

* Analysis on total contents.

$\uparrow$ Analysis on epididymal plasma.

$\$$ Different levels in caput and cauda.

Earlier investigations by Salisbury (1956) and Salisbury \& Cragle (1956) of electrolytes in the epididymal contents in the bull, and by White et al. (1961) in the ram, have shown that the balance between sodium and potassium, as well as the total concentration of these two electrolytes, is changed along the length of the epididymis. However, in a later publication this group (Scott et al., 1963) stated that the overall concentration of potassium remained about the same throughout the epididymis. This does not agree with our findings in the bull. A comparison between the present values and earlier reported investigations of the epididymal contents is given in Table 2. Not all of the present values could be directly compared with those obtained in earlier investigations. Many of the experiments were on the total content of the epididymis, including even the spermatozoa. In addition, in the earlier investigations the collection locations were not clearly defined. The investigations performed on sperm-free plasma, however (Sørensen \& Andersen, 1956; White et al., 1961; Scott et al., 1963) agree, in general, with the present investigation. It also agrees with 
Salisbury \& Cragle's (1956) if one considers the sperm concentration and known values of the electrolyte level of the ejaculated spermatozoa (Salisbury \& Cragle, 1956). However, the values they obtained from the testis differ considerably from the present values. This is probably due to a different collection technique.

It can be seen from the present investigation that the most dramatic change in ion balance occurs in the caput epididymidis side by side with a strong fluid resorption. The quotient of sodium/potassium changes, accordingly, in the head of the epididymis from $8 \cdot 3$ to $2 \cdot 1$. This latter value is then relatively constant in the corpus. Both sodium and potassium drop, in parallel, between corpus and cauda as the proportion sodium/potassium drops to $1 \cdot 2$. It seems clear that the shift of ion balance in the head of the epididymis depends upon a selective resorption in the epididymal epithelium. An exchange of sodium and potassium between the spermatozoa and the plasma is naturally worth considering, but it is probably, in comparison with the resorption, of secondary significance. The sum of sodium and potassium drops very slowly to the corpus epididymidis (E). In the cauda, one finds that the sum of both ions is strongly reduced. The preliminary investigations indicate that this drop is not compensated by other electrolytes but, instead, by an increase in protein and above all, in the cauda, by a strong increase in the glycerylphosphorylcholine.

\section{REFERENGES}

Bishop, M. W. H. (1961) Biology of spermatozoa. Sex and Internal Secretions. Ed. W. C. Young. Williams \& Wilkins, Baltimore.

Bishop, M. W. H. \& Walton, A. (1960) Spermatogenesis and the structure of mammalian spermatozoa. Marshall's Physiology of Reproduction, 3rd edn, vol. 1, pt. 2, p. 94. Ed. A. S. Parkes. Longmans Green, London.

Crabo, B. \& Gustafsson, B. (1963) Chemical investigations of epididymal sperm plasma (Abstr.). Int. J. Fertil. 8, 866.

Cragle, R. G., Salisbury, G. W. \& Muntz, J. H. (1958) Distribution of bulk and trace minerals in bull reproductive tract fluids and semen. 7. Dairy Sci. 41, 1273.

Cragle, R. G., Salisbury, G. W. \& VanDemark, N. L. (1958) Sodium, potassium, calcium, and chloride distribution in bovine semen. F. Dairy Sci. 41, 1267.

Gustafsson, B. (1964) Akinesia of bull spermatozoa associated with a functional disturbance in the epididymis. Acta vet. scand. (In press).

LAGERLöF, N. (1934) Morphologische Untersuchungen über Veränderungen im Spermabild und in den Hoden bei Bullen mit verminderten oder aufgehobener Fertilität. Acta path. microbiol. scand. Suppl. CI.

LAGERLöF, N. (1962) Thirty years experiences with a sperm laboratory for domestic animals. Zootecn. e Vet. 17, 343 .

Nicander, L. (1957) On the regional histology and cytochemistry of the ductus epididymidis in rabbits. Acta morph. neerl.-scand. 1, 99.

Nicander, L. (1958) Studies on the regional histology and cytochemistry of the ductus epididymidis in stallions, rams and bulls. Acta morph. neerl.-scand. 1, 337.

Salisbury, G. W. (1956) The function of epididymis of the bull. I. A theory for the activation of spermatozoan motility. Tijdschr. Diergenesk. 81, 616.

Salisbury, G. W. \& Cragle, R. G. (1956) Freezing point depressions and mineral levels of fluids of the ruminant male reproductive tract. Proc. IIIrd int. Congr. Anim. Reprod., Cambridge, p. 25.

Sanz, M. C. (1959) Physiko-chemische Grundlagen und apparative Neuentwicklungen in der quantitativen Ultramicroanalyse. Chimia, 13, 192.

Scotr, T. W., Wales, R. G., Wallace, J. G. \& White, I. G. (1963) Composition of ram epididymal and testicular fluid and biosynthesis of glycerylphosphorylcholine by the ram epididymis. 7. Reprod. Fertil. 6, 49.

Snedecor, G. W. (1946) Statistical methods, 4th edn. Iowa State College Press, Ames, Iowa. 
Sørensen, E. \& ANDERsen, S. (1956) The influence of sodium and potassium ions upon the motility of sperm cells. Proc. IIIrd int. Congr. Anim. Reprod., Cambridge, p. 45.

Swanson, E. W. \& BoYd, L. J. (1962) Factors affecting coiled-tail spermatozoa in the bull. Amer. $\mathcal{F}$. vet. Res. 23, 300.

White, I. G., Wallace, J. G., Wales, R. G. \& Scott, T. W. (1961) The occurrence and metabolism of glycerylphosphorylcholine in semen and the genital tract. Proc. IVth int. Congr. Anim. Reprod., The Hague, p. 266. 